\title{
Original
}

\section{Effects of Trait Anxiety on Breathlessness and Respiratory Patterns during Repeated Breath-holds}

\author{
Shunsuke SAKURAi ${ }^{1)}$, Yuri MasaOKA ${ }^{1)}$, Kazuo ItABASHI ${ }^{2)}$ \\ and Ikuo Homma ${ }^{1)}$
}

\begin{abstract}
Breathlessness is an unpleasant sensation related to respiration and is induced by hypercapnia or hypoxia. However, breathlessness is affected by psychological changes, especially anxiety. In this study we investigated how trait anxiety affected breathlessness induced by repetitive breath-holds. Breathlessness increased linearly with breath-hold trials. The subjects in the group of high trait anxiety (group H), whose scores were more than 43.2, had higher breathlessness as compared to the group of low trait anxiety (group $\mathrm{L})$. Tidal volume $\left(\mathrm{V}_{\mathrm{T}}\right)$ and $\mathrm{V}_{\mathrm{T}} / \mathrm{T}_{\mathrm{I}}$ also increased linearly with breath-hold trials, but there was no difference between group $\mathrm{H}$ and group L. This study suggests that respiratory effort increases while repetitive breath-holds augment breathlessness. This research also suggests that breathlessness may increase in a subject who has high trait anxiety.
\end{abstract}

Key words : breathlessness, breath-hold, trait anxiety

\section{Introduction}

Breathlessness or dyspnea is a subjective feeling of discomfort and is a common symptom in patients with cardiopulmonary disease ${ }^{1)}$. There are many studies showing the cause of breathlessness. Chemoreceptors or mechanoreceptors activated in the respiratory control system are capable of causing breathlessness. It is still unknown whether hypoxia induces breathlessness. Breathlessness decreased and exercise tolerance improved when oxygen was applied to patients with chronic obstructive pulmonary disease ${ }^{2)}$. Contrary to hypoxia, hypercapnia has been proven to induce breathlessness ${ }^{3)}$. The sense of effort is also one of the possible causes of breathlessness. Breathlessness increased parallel to the sense of effort with an increase of respiratory resistive load ${ }^{4}$.

Breathlessness may also be related to individual arousal, attention and anxiety levels and these can be additional factors for an increase of breathlessness and ventilatory responses to sensory stimulations. It is well known that a central pattern generator for respiration exists

\footnotetext{
1) Department of Physiology, Showa University School of Medicine, 1-5-8 Hhatanodai, Shinagawa-ku, Tokyo 142-8555, Japan.

2) Department of Pediatrics, Showa University School of Medicine.
} 
in the brainstem, but the respiratory pattern is also influenced by activation of the limbic structure ${ }^{5)}$. In an awakened state, $\mathrm{CO}_{2}$ inhalation alters respiratory patterns primarily by the stimulation of chemoreceptors, but final respiratory output is generated by the interaction between metabolism requirements and inputs from the limbic structure. It has been reported that subjective air hunger sensitivity is common in high trait anxious subjects ${ }^{6)}$. Also, there is a positive correlation between breathlessness and anxiety levels both in normal controls and in patients with hyperventilation syndrome ${ }^{7)}$. In addition, repeated experiments of breathlessness induced by $\mathrm{CO}_{2}$ inhalation influence the subjective feeling and ventilator responses ${ }^{6)}$.

In this study, we investigated whether breathlessness was related to individual anxiety levels and whether the repeated experiences of breathlessness increased breathlessness induced by the combined effects of $\mathrm{CO}_{2}$ inhalation and breath-hold.

\section{Materials and Methods}

Seven normal subjects (all males; mean age, 31.6 years) participated in this study. All subjects gave informed consent and the study was approved by the Ethics Committee of Showa University School of Medicine. All subjects completed Spielberger's State-Trait Anxiety Inventory (STAI ${ }^{8)}$ before the experiment. The trait anxiety scale in the STAI was used to assess their anxiety personality.

After the STAI assessment, the subjects were seated to rest for the next experiment. A face mask with a transducer for measuring respiratory flow and volume with a flow meter was attached to each subject (AE280, Minato Medical Science, Osaka, Japan). The end tidal $\mathrm{CO}_{2}$ concentration was measured with a $\mathrm{CO}_{2}$ analyzer (IH31, Sanei, Japan). The subjects inhaled the gas mixture of $5 \%$ carbon dioxide $+95 \%$ oxygen through a one-way valve connected to the mask. Fig. 1 shows the experimental setup of the study. The subjects were instructed to breath-hold at the end of expiration for 10 seconds after spontaneous breathing for 20 seconds. They repeated this trial 10 times. We asked the subjects about their breathlessness by use of a visual analogue scale (VAS) after each breath-hold. Respiratory flow and volume together with the $\mathrm{CO}_{2}$ concentration were continuously measured and stored in a computer. Tidal volume $\left(\mathrm{V}_{\mathrm{T}}\right)$, inspiratory time $\left(\mathrm{T}_{\mathrm{I}}\right)$ and end tidal $\mathrm{CO}_{2}$ concentration $\left(\mathrm{ETCO}_{2}\right)$ of the first breath after each breath-hold was fed into an analyzer.

As the trait anxiety score of each subject had an effect on respiration ${ }^{9)}$, we divided the subjects into two groups. The mean score after the STAI assessment for all subjects was 43.2. The subjects with a score of more than 43.2 were placed in a high trait anxiety group (group $\mathrm{H} ; \mathrm{N}=4$ ), and a score of less than 43.2 were in a low trait anxiety group (group $\mathrm{L} ; \mathrm{N}=3)$. There was a significant difference in trait anxiety scores between group $\mathrm{H}$ and group $\mathrm{L}(P=0.03)$.

For statistical analysis, a software package (SPSS, SPSS Japan) was employed. Two-way repeated measures analysis of variance (ANOVA) was used to test for the effect of $\mathrm{CO}_{2}$ 


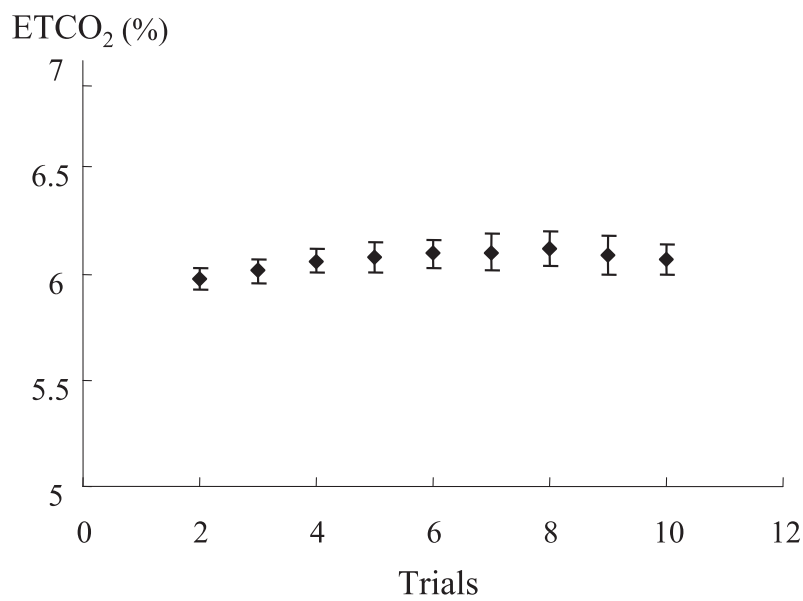

Fig. 1 End tidal $\mathrm{CO}_{2}$ concentration $\left(\mathrm{ETCO}_{2}\right)$ of 9 trials. Data indicates the mean \pm SD of all subjects

and the effect of trait anxiety. Greenhouse-Geisser adjustment of the degree of freedom was applied to ANOVA to correct for violation of the assumption of sphericity.

\section{Results}

There was no significant difference in the $\mathrm{ETCO}_{2}$ concentration of the first breath after each 10 second breath-hold (Fig. 1).

Breathlessness expressed as VAS progressively increased with trials. VAS was divided by the $\mathrm{ETCO}_{2}$ of the first breath after breath-hold to avoid the effect of $\mathrm{CO}_{2}$ on the sensation. The subjects were divided into two groups. One group (group H) had a higher trait anxiety score of more than 43 (mean $\pm \mathrm{SD}: 48.75 \pm 4.4$ ), and the other group (group L) had a lower score of less than $43($ mean $\pm \mathrm{SD}: 36.0 \pm 5.6)$. $\mathrm{VAS} / \mathrm{ETCO}_{2}$ after the first breath-hold was $3.75 \pm 2.21$ (mean $\pm \mathrm{SD}$ ) in group $\mathrm{H}$ and $3.22 \pm 1.27$ (mean $\pm \mathrm{SD}$ ) in group L. Those after the $10^{\text {th }}$ breath-hold were $12.35 \pm 1.14$ (mean $\pm \mathrm{SD}$ ) in group $\mathrm{H}$ and 8.42 $\pm 1.39($ mean $\pm \mathrm{SD})$ in group L. $\mathrm{VAS} / \mathrm{ETCO}_{2}$ after the $10^{\text {th }}$ trial was significantly higher than that after the $1^{\text {st }}$ trial in both groups. $\mathrm{VAS} / \mathrm{ETCO}_{2}$ in the $\mathrm{H}$ group was significantly higher than that in the $\mathrm{L}$ group after both the $1^{\text {st }}$ trial and the $10^{\text {th }}$ trial. $\mathrm{VAS} / \mathrm{ETCO}_{2}$ was gradually increased by the reiterate trials except for the $1^{\text {st }}$ trial. The increased value from the $1^{\text {st }}$ trial and the $2^{\text {nd }}$ trial was larger compared with the values between the other trials. Regression lines of $\mathrm{VAS} / \mathrm{ETCO}_{2}$ from the $2^{\text {nd }}$ to the $10^{\text {th }}$ trials were $\mathrm{Y}=0.61 \mathrm{X}+7.5\left(\mathrm{R}^{2}\right.$ : $0.946)$ in group $\mathrm{H}$ and $\mathrm{Y}=0.46 \mathrm{X}+4.7\left(\mathrm{R}^{2}: 0.9\right)$ in group $\mathrm{L}$. Both lines have significant correlations. The slope of the $\mathrm{H}$ group is steeper than that of the $\mathrm{L}$ group (Fig. 2).

The breathing patterns also changed with the trials. $\mathrm{V}_{\mathrm{T}}$ progressively increased in the reiterate trials of both groups. $\mathrm{V}_{\mathrm{T}}$ after the $1^{\text {st }}$ trial was $1.09 \pm 0.14($ mean $\pm \mathrm{SD})$ in group $\mathrm{H}$ and $0.73 \pm 0.21($ mean $\pm \mathrm{SD})$ in group $\mathrm{L} . \mathrm{V}_{\mathrm{T}}$ after the $10^{\text {th }}$ trial was $1.96 \pm 0.69(\mathrm{mean} \pm \mathrm{SD})$ 


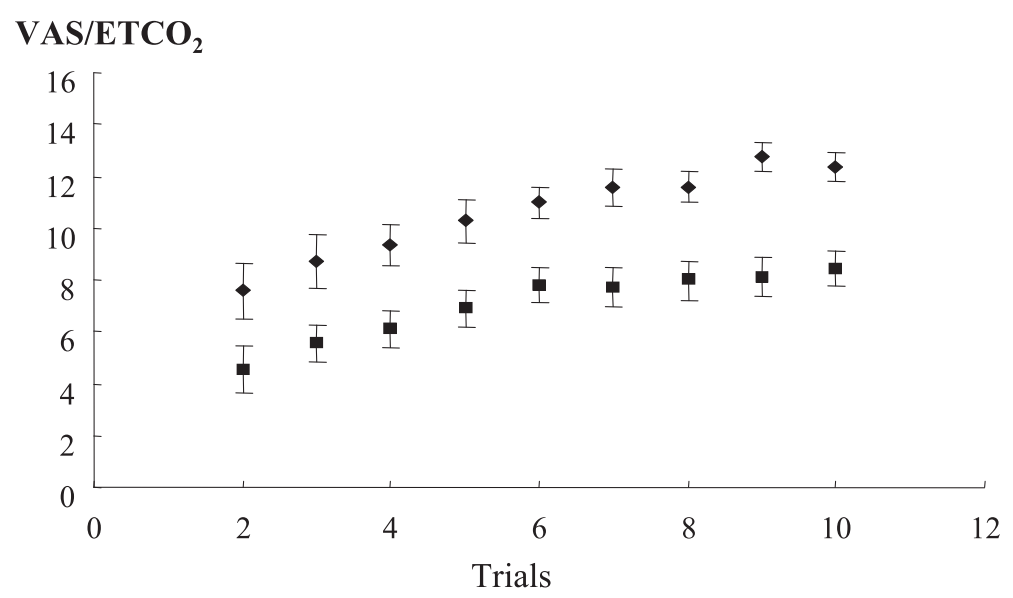

Fig. 2 Regression lines of visual analogue scale/end tidal $\mathrm{CO}_{2}$ concentration $\left(\mathrm{VAS} / \mathrm{ETCO}_{2}\right)$ from the $2^{\text {nd }}$ to $10^{\text {th }}$ trials. Group $\mathrm{H}$ (closed diamonds) ; group L (closed squares)

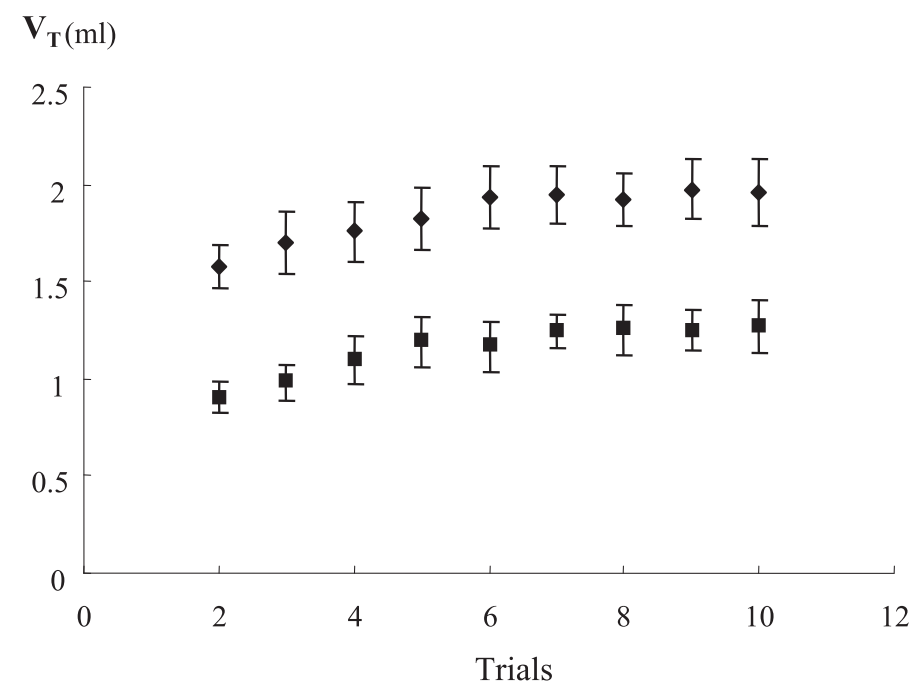

Fig. 3 Tidal volume $\left(\mathrm{V}_{\mathrm{T}}\right)$ of 9 trials for group $\mathrm{H}$ and group $\mathrm{L}$. Group H (closed diamonds); group L (closed squares)

in group $\mathrm{H}$ and $1.27 \pm 0.46$ (mean $\pm \mathrm{SD}$ ) in group $\mathrm{L}$. $\mathrm{V}_{\mathrm{T}}$ after the $10^{\text {th }}$ trial was significantly higher than that of the $1^{\text {st }}$ trial in both groups. $\mathrm{V}_{\mathrm{T}}$ in group $\mathrm{H}$ was significantly higher than that of group $\mathrm{L}$ both after the $1^{\text {st }}$ and the $10^{\text {th }}$ trials. The regression line of $\mathrm{V}_{\mathrm{T}}$ from the $2^{\text {nd }}$ to the $10^{\text {th }}$ trial was $\mathrm{Y}=0.05 \mathrm{X}+1.61\left(\mathrm{R}^{2}: 0.85\right)$ in group $\mathrm{H}$ and $\mathrm{Y}=0.04 \mathrm{X}+0.93\left(\mathrm{R}^{2}\right.$ : 0.84) in group L. Both lines had significant correlations (Fig. 3).

$\mathrm{V}_{\mathrm{T}} / \mathrm{T}_{\mathrm{I}}$ is generally used to express the value of respiratory central output. $\mathrm{V}_{\mathrm{T}} / \mathrm{T}_{\mathrm{I}}$ after the $1^{\text {st }}$ trial was $0.63 \pm 0.08($ mean $\pm S D)$ in group $\mathrm{H}$ and $0.46 \pm 0.07$ in group $\mathrm{L} . \mathrm{V}_{\mathrm{T}} / \mathrm{T}_{\mathrm{I}}$ after the $10^{\text {th }}$ trial was $1.23 \pm 0.18($ mean $\pm \mathrm{SD})$ in group $\mathrm{H}$ and $0.87 \pm 0.16($ mean $\pm \mathrm{SD})$ in 


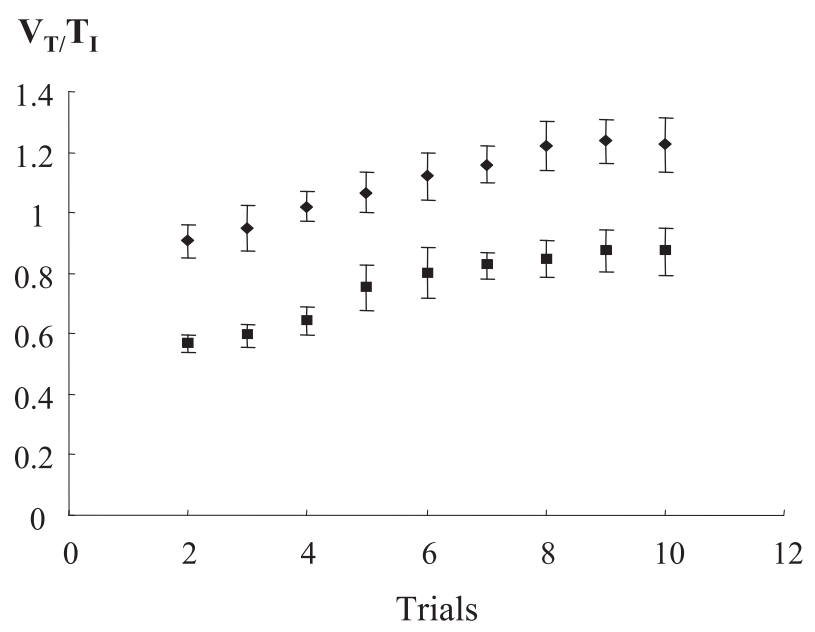

Fig. 4 Tidal volume/inspiratory time $\left(\mathrm{V}_{\mathrm{T}} / \mathrm{T}_{\mathrm{I}}\right)$ of 9 trials for group $\mathrm{H}$ and group L. Group $\mathrm{H}$ (closed diamonds); group L (closed squares)

group $\mathrm{L} . \quad \mathrm{V}_{\mathrm{T}} / \mathrm{T}_{\mathrm{I}}$ after the $10^{\text {th }}$ trial was significantly larger than that after the $1^{\text {st }}$ trial both in group $\mathrm{H}$ and group $\mathrm{L}$. $\mathrm{V}_{\mathrm{T}} / \mathrm{T}_{\mathrm{I}}$ in group $\mathrm{H}$ was significantly larger than that in group $\mathrm{L}$ both after the $1^{\text {st }}$ and the $10^{\text {th }}$ trials. The increased value from the $1^{\text {st }}$ to the $2^{\text {nd }}$ trial was larger compared with values of other trials. The regression line of $\mathrm{V}_{\mathrm{T}} / \mathrm{T}_{\mathrm{I}}$ from the $2^{\text {nd }}$ to the $10^{\text {th }}$ trial was $\mathrm{Y}=0.04 \mathrm{X}+0.9\left(\mathrm{R}^{2}: 0.95\right)$ in group $\mathrm{H}$ and $\mathrm{Y}=0.04 \mathrm{X}+0.5\left(\mathrm{R}^{2}: 0.912\right)$ in group L. Both lines had significant correlations, but the slopes of these 2 lines showed no significant differences (Fig. 4).

\section{Discussion}

The purpose of this study was to identify the factors that increase breathlessness and those that cause breathlessness with repetitive stimulation. Breathlessness, which is a more general term used mostly in clinics, is a major symptom of cardiopulmonary disease but can occur in normal subjects during exercise. It is known that breath-holding causes breathlessness and the longer the breath-hold time the higher the level of breathlessness ${ }^{10)}$. Most studies of breathlessness during breath-hold measured breathlessness tolerance ${ }^{11,12)}$. However, we investigated whether repetitive breath-holds affected breathlessness.

In this study, we have clearly demonstrated that breathlessness is accumulated by repetitive breath-holds. Breathlessness during a 10 second breath-hold was linearly increased by repetitive breath-holds at intervals of 20 seconds. There are several factors involved in increasing breathlessness. For example, breathlessness is increased by the stimulation of chemoreceptors by $\mathrm{CO}_{2}$ or hypoxia ${ }^{10,13,14)}$, or by the stimulation of mechanoreceptors by inflation or deflation of the lungs ${ }^{15)}$. In the present study, the $\mathrm{ETCO}_{2}$ at the first breath after the breath-hold did not increase with the trials. Therefore, $\mathrm{CO}_{2}$, which is the most 
effective factor in breathlessness, did not contribute to the progressive increase of breathlessness. There may be no change in mechanoreceptors with repetitive trials. Also, there may be other factors causing an increase in breathlessness with repetitive trials, such as a sense of effort, for example ${ }^{4)}$.

Breathlessness is the sense induced by the corollary discharges from respiratory motor cortexes. Therefore, breathlessness may be reflected in respiratory motor output, such as $\mathrm{V}_{\mathrm{T}}$ or $\mathrm{V}_{\mathrm{T}} / \mathrm{T}_{\mathrm{I}}$, which also increased with trials. However, there was no significant difference in increased $V_{T}$ or $V_{T} / T_{I}$ between groups $H$ and $L$. Contrary to $V_{T}$ and $V_{T} / T_{I}$, the increase of $\mathrm{VAS} / \mathrm{ETCO}_{2}$ in the trials was different in groups $\mathrm{H}$ and $\mathrm{L}$. The increased value of breathlessness in group $\mathrm{H}$ was higher than the value in group $\mathrm{L}$. Respiratory sensation is reported to be dependent on the subject's emotional state ${ }^{5,16)}$ and we found that anxiety changes respiratory patterns and sensation. Also, the progressive increase of breathlessness induced by the repetitive trials of breath-hold may be induced by the increase of inspiratory effort. Although this study used a limited number of subjects, we have demonstrated that trait anxiety may enhance breathlessness.

\section{References}

1) O’Donnell DE, Banzett RB, Carrieri-Kohlman V, Casaburi R, Davenport PW, Gandevia SC, Gelb AF, Mahler DA and Webb KA: Pathophysiology of dyspnea in chronic obstructive pulmonary disease : a roundtable. Proc Am Thorac Soc $4: 145-168$ (2007)

2) Woodcock AA, Gross ER and Geddes DM : Oxygen relieves breathlessness in "pink puffers". Lancet 1:907909 (1981)

3) Chonan T, Mulholland MB, Cherniack NS and Altose MD: Effect of voluntary constraining of thoracic displacement during hypercapnia. J Appl Physiol 63 : 1822-1828 (1987)

4) Killian KJ, Gandevia SC, Summers E and Campbell EJ : Effect of increased lung volume on perception of breathlessness, effort, and tension. J Appl Physiol 57 : 686-691 (1984)

5) Masaoka $\mathrm{Y}$ and Homma $\mathrm{I}$ : The effect of anticipatory anxiety on breathing and metabolism in humans. Respir Physiol 128 : 171-177 (2001)

6) Li W, Daems E, Van de Woestijne KP, Van Diest I, Gallego J, De Peuter S, Bogaerts K and Van den Bergh $\mathrm{O}$ : Air hunger and ventilation in response to hypercapnia: effects of repetition and anxiety. Physiol Behav 88 : 47-54 (2006)

7) Masaoka Y, Jack S, Warburton CJ and Homma I : Breathing patterns associated with trait anxiety and breathlessness in humans. Jpn J Physiol $54: 465-470$, (2004)

8) Spielberger CD : Manual for the State-Trait Anxiety Inventory (STAI). Consulting Psychologists Press, Polo Alto (1983)

9) Homma I and Masaoka Y: Breathing rhythms and emotions. Exp Physiol 93 : 1011-1021 (2008)

10) Banzett RB, Lansing RW, Evans $\mathrm{KC}$ and Shea SA : Stimulus-response characteristics of $\mathrm{CO}_{2}$-induced air hunger in normal subjects. Respir Physiol 103 : 19-31 (1996)

11) Flume PA, Eldridge Fl, Edwards LJ and Houser LM: The fowler breathholding study revisited: continuous rating of respiratory sensation. Respir Physiol 95 : 53-66 (1994)

12) Nishino $T$, Sugimori $\mathrm{K}$ and Ishikawa $\mathrm{T}$ : Changes in the period of no respiratory sensation and total breathholding time in successive breath-holding trials. Clin Sci (Lond) 91:755-761 (1996)

13) Banzett RB, Lansing RW, Reid MB, Adams L and Brown R: "Air hunger" arising from increased $\mathrm{PCO}_{2}$ in mechanically ventilated quadriplegics. Respir Physiol 76:53-67 (1989) 
14) Banzett RB, Lansing RW, Brown R, Topulos GP, Yager D, Steele SM, Londono B, Loring SH, Reid MB and Adams L: 'Air hunger' from increased $\mathrm{PCO}_{2}$ persists after complete neuromuscular block in humans. Respir Physiol 81 : 1-17 (1990)

15) Manning HL, Shea SA, Schwartzstein RM, Lansing RW, Brown R and Banzett RB : Reduced tidal volume increases 'air hunger' at fixed $\mathrm{PCO}_{2}$ in ventilated quadriplegics. Respir Physiol 90 : 19-30 (1992)

16) Wilhelm FH, Gevirtz R and Roth WT: Respiratory dysregulation in anxiety, functional cardiac, and pain disorders. Behav Modif $25:$ 513-545 (2001)

[Received January 27, 2009 : Accepted February 6, 2009] 